\title{
Do methane emissions converge? Evidence from global panel data on production- and consumption-based emissions
}

\author{
Octavio Fernández-Amador ${ }^{1}$ - Doris A. Oberdabernig ${ }^{1,2}{ }_{(D)}$. \\ Patrick Tomberger ${ }^{1}$
}

Received: 20 July 2021 / Accepted: 18 October 2021 / Published online: 9 December 2021

(c) The Author(s) 2021

\begin{abstract}
Methane emissions are the second most important contributor to global warming. Knowledge about the dynamics of methane emissions facilitates the formulation of climate policies and the understanding of their consequences. We investigate whether methane emissions released from production and embodied in consumption converge within and across regions. Our estimates rely on global panel data on methane per capita and methane intensities over 1997-2014. We find that emissions converge within countries. The short half-lives show that the emissions of countries are close to their steady states. There is no evidence for international convergence of aggregate emissions. Yet, convergence of emissions across regions occurs in a number of economic sectors. Our results highlight the difficulties to achieve methane abatement in the medium run. The formulation of climate policies should take into account the sectoral specificity of the dynamics of methane emissions.
\end{abstract}

Keywords Methane emissions · Beta convergence $\cdot$ Emission footprints $\cdot$ Emission intensities $\cdot$ Sectoral analysis

\footnotetext{
The authors thank the participants of the SWSR for inspiring discussions. All of the authors acknowledge support of the NRP 73 project Switzerland's Sustainability Footprint: Economic and Legal Challenges, Grant No. 407340-172437, University of Bern, supported by the Swiss National Science Foundation (SNSF) within the framework of the National Research Programme "Sustainable Economy: resource-friendly, future-oriented, innovative" (NRP 73).
}

$\bowtie$ Doris A. Oberdabernig doris.oberdabernig@uibk.ac.at

Octavio Fernández-Amador octavio.fernandez@wti.org

Patrick Tomberger patrick.tomberger@wti.org

1 World Trade Institute, University of Bern, Hallerstrasse 6, 3012 Bern, Switzerland

2 University of Innsbruck, Universitätsstraße 15, 6020 Innsbruck, Austria 
JEL Classification F64 · O44 · Q54 · Q56

\section{Introduction}

The Paris Agreement delegates to national governments the formulation of greenhouse gas (GHG) abatement targets, implemented through Nationally Determined Contributions (NDCs; Jacquet and Jamieson 2016; Nieto et al. 2018; Keohane and Victor 2016). This bottom-up approach to emission abatement calls for a better understanding of national GHG emissions trajectories (see also Joeri Rogelj 2016). The debate on GHG emissions so far has mainly focused on carbon dioxide $\left(\mathrm{CO}_{2}\right)$ emissions, whereas much less attention has been paid to the second most important GHG, methane $\left(\mathrm{CH}_{4}\right)$.

Global anthropogenic $\mathrm{CH}_{4}$ releases are comparable in magnitude to $\mathrm{CO}_{2}$ emissions in terms of their global warming potential (GWP) over a period of 20 years (Fernández-Amador et al. 2020b). Yet, $\mathrm{CH}_{4}$ emissions differ from $\mathrm{CO}_{2}$ emissions in important aspects. $\mathrm{CH}_{4}$ has a much shorter atmospheric lifetime than $\mathrm{CO}_{2}$ and a considerably larger GWP per ton of emissions, which is concentrated at the beginning of its atmospheric life (IPCC 2014). In contrast to $\mathrm{CO}_{2}$, the bulk of anthropogenic $\mathrm{CH}_{4}$ emissions is attributed to few economic activities with very heterogeneous abatement potentials and costs, such as cattle breeding, drilling and transportation of fossil fuels, waste management, and rice cultivation. This impacts on the geographic distribution of emissions, with developing countries contributing a major part to global $\mathrm{CH}_{4}$ releases (Fernández-Amador et al. 2020b). Also, the determinants of $\mathrm{CH}_{4}$ emissions differ from those of $\mathrm{CO}_{2}$ emissions, notably the effect of economic growth and of income per capita (Fernández-Amador et al. 2018, 2020a). These differences, and the problems connected to the conversion of different GHGs to a common scale (Fesenfeld et al. 2018), have been one of the stumbling blocks for negotiations about the rules for international GHG markets under Article 6 of the Paris Agreement, at the 25th Conference of the Parties (COP25) in Madrid (Carbon Brief 2019). Because mitigation of $\mathrm{CH}_{4}$ emissions is especially important for limiting climate change in the near term (Jackson 2009; Shindell et al. 2012, 2017), more attention to $\mathrm{CH}_{4}$ emissions is warranted.

Knowledge about convergence dynamics of $\mathrm{CH}_{4}$ emissions is important in at least three aspects: it allows to evaluate equity concerns about the effects of climate policy, to better understand the costs related to such policy, and to provide information for climate models. If emissions converged internationally, equity concerns related to international climate policy aimed at changing the distribution of emissions across countries could be reduced (see Aldy 2006; Barassi et al. 2011). By contrast, the absence of international convergence could point to persistent structural differences across countries, such that international climate policy would introduce substantial reallocation of emissions (Aldy 2006). Thus, testing for international convergence of emissions is relevant to understand the distributional dynamics of emissions and countries' participation and position in multilateral agreements.

Furthermore, the focus on NDCs inherent in the Paris Agreement emphasizes the importance of country-specific convergence dynamics. Country-specific convergence provides information about how far a country's emissions are from their equilibrium 
(steady-state) value. This information allows to assess emissions in relation to a country's long-run economic growth and to determine its long-run national contribution. This information is also relevant to evaluate the costs of emission reduction targets. When a country is close to its equilibrium path of emissions and that path has revealed to be unsustainable, a large share of emission reduction will be associated with the equilibrium path. By contrast, when a country is far from its steady state, a larger share of emission reduction will be associated with the transition dynamics. In general, for a given level of emission reduction, the costs of abatement will be larger if countries are closer to their steady-state level of emissions.

Moreover, the hypothesis of convergence usually underlies projections of climate models that are used to evaluate the effects of climate policy (Romero-Ávila 2008; Barassi et al. 2011). Empirical studies on the convergence of GHG emissions can provide evidence whether this assumption is justified.

The empirical literature has tested for convergence of GHG emissions per capita and per unit of value added (emission intensity), mainly focusing on $\mathrm{CO}_{2}$ emissions (Pettersson et al. 2014; Stern 2017). Although most studies found evidence for convergence or convergence clubs for $\mathrm{CO}_{2}$ per capita, some rejected the existence of convergence. ${ }^{1}$ Some countries, such as China and India, have defined their NDCs in terms of emission intensities. Emission intensities can be more directly addressed by national environmental policies than emissions per capita, because the economic scale of production, affecting emissions per capita, is determined not only by local but also by global demand. Thus, it is informative to assess whether missing convergence of emissions per capita is driven by missing convergence of emission intensities. If emission intensities do not converge, policies aimed at the adoption of less emission intensive production methods may contribute to emission abatement, especially in developing countries that have higher emission intensities. Empirical studies on the convergence of $\mathrm{CO}_{2}$ intensities detected evidence for convergence (Camarero et al. 2013; Panopoulou and Pantelidis 2009; Fernández-Amador et al. 2019).

Most empirical studies have focused on production-based emissions, because of the political emphasis on territorial emissions to determine responsibility for emissions; ${ }^{2}$ however, the interest in consumption-based emissions is rapidly

\footnotetext{
1 For studies that find evidence for convergence or convergence clubs, see Strazicich and List (2003), Nguyen (2005), Aldy (2006), Barassi et al. (2011), Romero-Ávila (2008), Westerlund and Basher (2008), Panopoulou and Pantelidis (2009), Brock and Taylor (2010), Jobert et al. (2010), Ordás Criado and Grether (2011), Camarero et al. (2013), Yavuz and Yilanci (2013) and Fernández-Amador et al. (2019). For studies that do not find evidence for convergence, see Barassi et al. (2008) and Nourry (2009).

2 Production-based emissions convergence has been evaluated using tests for $\beta, \sigma$, and stochastic convergence. For $\beta$-convergence of $\mathrm{CO}_{2}$ emissions, see, e.g., Strazicich and List (2003), Nguyen (2005), Brock and Taylor (2010), Jobert et al. (2010), Fernández-Amador et al. (2019), Karakaya et al. (2019), for $\sigma$ convergence see Aldy (2006), Panopoulou and Pantelidis (2009), Brock and Taylor (2010), Ordás Criado and Grether (2011), Camarero et al. (2013) and for stochastic convergence Strazicich and List (2003), Nguyen (2005), Aldy (2006), Romero-Ávila (2008), Barassi et al. (2008), Westerlund and Basher (2008), Nourry (2009), Barassi et al. (2011), Yavuz and Yilanci (2013). Tests for $\sigma$ and stochastic convergence are not applicable when testing for convergence of consumption-based emissions, since data availability is restricted in time by the availability of input-output (IO) tables needed to calculate consumption-based emissions. Also, for global samples of countries GHG emissions are likely to be affected by transition dynamics, which may pose issues for tests of stochastic convergence (Bernard and Durlauf 1996).
} 
increasing. ${ }^{3}$ Consumption-based emission footprints assign the responsibility of emissions released in the production of products to the country in which final consumption takes place, and thus account for the spatial separation of production and consumption in a globalized world. Hence, convergence in emissions embodied in consumption per capita may address equity concerns even more directly than convergence of production-based emissions per capita (see Lenzen et al. 2012). Convergence of $\mathrm{CO}_{2}$ embodied in consumption across countries has been evaluated by Fernández-Amador et al. (2019) and Karakaya et al. (2019), who found evidence for convergence.

In this paper, we provide a comprehensive analysis of convergence patterns of $\mathrm{CH}_{4}$ emissions. Our estimates are based on global panel data on anthropogenic $\mathrm{CH}_{4}$ emissions for 66 countries and 12 composite regions in the period from 1997 to 2014, available from Fernández-Amador et al. (2020b). Our analysis contributes to the literature in several ways. First, we assess convergence of $\mathrm{CH}_{4}$ emissions within regions, toward individual-specific steady states, and across regions, toward international steady states. Second, we evaluate whether convergence of $\mathrm{CH}_{4}$ intensities drives convergence of $\mathrm{CH}_{4}$ per capita. Third, we take different viewpoints on the responsibility for emissions and evaluate convergence of emissions from a production-based and from a consumption-based perspective. Finally, we take into account the importance of sectoral specialization for methane emissions and analyze convergence of emissions not only economy-wide but also for seven broad economic sectors.

The specification of our econometric model is motivated by the theoretical models of Brock and Taylor (2010) and Ordás Criado et al. (2011), which boil down to models of $\beta$-convergence.

Following Fernández-Amador et al. (2019), we implement a Bayesian structural model that addresses potential sources of endogeneity, accommodates heteroscedasticity in the data, and allows to test for group-specific convergence patterns. We test for the existence of group-specific convergence of $\mathrm{CH}_{4}$ emissions for the European Union (EU), the Organisation of Economic Co-Operation and Development (OECD), and Annex I countries to the United Nations Framework Convention on Climate Change (UNFCCC) that ratified the Kyoto Protocol.

Our results indicate rapid convergence of all $\mathrm{CH}_{4}$ inventories toward individualspecific steady states, suggesting that emission reductions will mainly be associated with long-run equilibrium growth paths. Convergence of $\mathrm{CH}_{4}$ emissions toward global steady states is concentrated in specific economic sectors, and shows up on the economy-wide level only for $\mathrm{CH}_{4}$ per capita embodied in consumption. Evidence for different group-specific convergence dynamics is weak and is present only for OECD and Annex I countries in very few economic sectors.

Moreover, our findings reveal differences in international convergence dynamics across emission inventories at the sectoral level. While production-based emission intensities of most sectors converge across countries, production-based emissions per capita do not, indicating that structural differences across countries may persist over

\footnotetext{
3 See, e.g., Peters (2008), Peters and Hertwich (2008), Wiedmann (2009), Wiedmann et al. (2011), Wiedmann et al. (2015), Davis and Caldeira (2010), Lenzen et al. (2012), Blanco et al. (2014), and Fernández-Amador et al. (2016).
} 
time. Despite the lack of convergence in production-based $\mathrm{CH}_{4}$ per capita across countries, international trade allows $\mathrm{CH}_{4}$ per capita embodied in consumption to converge. Overall, our findings highlight that current patterns of methane emissions are unsustainable and that a large share of emission reductions will be related to the longrun equilibrium path, implying that mitigation policies could be costly. The sectoral differences in the convergence dynamics of methane inventories suggest that a differentiated, sectoral approach for multilateral agreements on methane emissions may be beneficial.

The paper is structured as follows. Section 2 outlines the empirical model and discusses the data. Section 3 summarizes the results for economy-wide and sectoral convergence of the four different methane inventories to individual-specific and global steady states. Section 4 provides a discussion of the findings and concludes.

\section{Econometric model and data}

\subsection{The model}

We test for $\beta$-convergence using a Bayesian structural model developed by FernándezAmador et al. (2019), which is based on the Green Solow model (Brock and Taylor 2010) and the neoclassical growth model by Ordás Criado et al. (2011). In a nutshell, the test for $\beta$-convergence toward individual-specific steady states is implemented as

$$
\begin{aligned}
G_{i, t, s}= & \beta E_{i, t-s}+\sum_{j}\left[\beta_{j} d_{j} E_{i, t-s}\right]+\pi_{0} g_{i, t, s}+\pi_{1} Y_{i, t-s}+\sum_{r}\left[\lambda_{r} z_{r, i, t-s}\right] \\
+ & \delta_{t}+\alpha_{i}+\epsilon_{1, i t} \\
& g_{i, t, s}=\alpha_{i v}+\beta_{i v} L\left(g_{i, t, s}\right)+\epsilon_{2, i t}
\end{aligned}
$$

The dependent variable in Eq. (1) is the average growth rate of emissions in region $i$ over the period $t-s$ and $t\left(G_{i, t, s}\right)$, alternatively released from production and embodied in consumption, both per capita and per unit of value added. $G_{i, t, s}$ depends on the logarithm of lagged emissions $\left(E_{i, t-s}\right)$, interactions of $E_{i, t-s}$ with dummy indicators for EU, OECD, and Annex I countries that ratified the Kyoto Protocol $\left(d_{j}\right)$, the average growth rate and the lagged logarithm of real GDP per capita $\left(g_{i, t, s}\right.$ and $\left.Y_{i, t-s}\right)$, a set of control variables $\left(z_{r, i, t-s}\right)$, and time- and individual-specific effects $\left(\delta_{t}\right.$ and $\left.\alpha_{i}\right)$. The control variables are motivated by previous literature (Richmond and Kaufmann 1997; Frankel and Rose 2005; Aichele and Felbermayr 2012, 2015; Fernández-Amador et al. 2017, 2019) and consist of the logarithm of population density, trade openness, a political regime index, the share of nuclear energy and fossil fuels in energy production, fossil rents as share of GDP, and value-added shares of seven sectors: livestock, energy, manufacturing, service, transport, and public administration, with the agricultural sector being the base category.

The average growth rates of emissions and GDP per capita are calculated as the difference of logarithms over $t-s$ and $t$, divided by the number of years, $s$. In our 
setting, $s$ equals 3-4 years, which avoids potential upward bias in the estimated speed of convergence that could result from short-term fluctuations in emissions (Ordás Criado et al. 2011). Because the growth rate of GDP per capita may be jointly determined with the growth rate of emissions over the same period, we account for its potential endogeneity in Eq. (2). Following Barro and Sala-i-Martin (2004), we instrument the growth rate of GDP per capita with its growth rate in the previous period, $L\left(g_{i, t, s}\right)$, where $L(\cdot)$ denotes the lag operator.

The parameter associated with lagged emissions, $\beta$, is of particular interest. Specifically, $\beta<0$ provides evidence for conditional $\beta$-convergence. Furthermore, the possibility of group-specific convergence is evaluated by including the interactions of lagged emissions with indicators for group membership in the EU, OECD, and Annex $\mathrm{I}\left(d_{j} E_{i, t-s}\right)$. The importance of group-specific convergence is tested using stochastic search variable selection (SSVS) priors (George and McCulloch 1993), which allow to derive posterior inclusion probabilities (PIPs) for the group-specific convergence terms. We conclude that there is evidence for a specific convergence pattern of group $j$ under two conditions: $P I P_{j}>0.5$ and $\beta_{j} \neq 0$.

The system formed by Eqs. (1)-(2) is solved by a Cholesky rotation to represent the model in recursive form (see Lopes and Polson 2014; Fernández-Amador et al. 2019). Cross-sectional heteroscedasticity is operationalized through endogenously estimated individual-specific variances, modeled as a scale mixture of multivariate normal distributions; the estimate of the parameter $v$, which governs the distribution of the individual-specific weights, provides information about the degree of crosssectional heteroscedasticity. All priors are specified as in Fernández-Amador et al. (2019), to which we refer for details.

Additionally to the specification explained above, we test for $\beta$-convergence toward international steady states conditional on socio-economic and political variables, by estimating the system formed by Eqs. (1)-(2) omitting the individual-specific effects, $\alpha_{i}$. Finally, we perform all the estimations using methane emissions at the sectoral level as the dependent variable. ${ }^{4}$

\subsection{The data}

Global panel data on anthropogenic $\mathrm{CH}_{4}$ emissions, disaggregated to 66 countries and 12 composite regions are available from Fernández-Amador et al. (2020b) for the years 1997, 2001, 2004, 2007, 2011, and 2014. The data cover production- and consumption-based $\mathrm{CH}_{4}$ emissions. Production-based emissions correspond to territorial emissions, which constitute the basis for international agreements according to the polluter pays principle, while consumption-based emission inventories account for emissions released across the whole supply chain, allocating the responsibility for emissions to the consumer of final products. Apart from total releases of emissions, the

\footnotetext{
4 We also implement a sensitivity analysis on the degree of heteroscedasticity of the model for economywide emissions. Two experiments are carried out. First, we specify alternative values of the hyperprior of the hyperparameter $v$. Second, we impose different values for $v$ exogenously. These experiments highlight the robustness of our results. See Appendix A.4.
} 
database provides information on emissions per capita and emissions per unit of value added (emission intensities). Because emissions per capita are determined by emissions per unit of value added times value added per capita, the distinction between the two emission aggregates allows to evaluate whether changes in emissions per capita are driven by changes in emission intensities.

The data also provide information on emissions from 57 economic sectors, which are aggregated to seven broader economic sectors-namely agriculture, livestock, manufacturing, services, energy, transport, and public administration. Most of the 57 sectors do not release $\mathrm{CH}_{4}$ or only account for a tiny share of $\mathrm{CH}_{4}$ emissions produced. The main sources of anthropogenic $\mathrm{CH}_{4}$ emissions are cattle farming and dairy (covered by the livestock sector); coal, oil, and gas production (energy sector); waste management (public administration sector); rice cultivation (agriculture sector); the transportation of fossil fuels (transport sector); and the petrochemical industry (manufacturing). ${ }^{5}$ Table 1 shows the average contribution of the seven broad sectors to aggregate $\mathrm{CH}_{4}$ emissions between 1997 and 2014, for production and consumptionbased emission inventories.

Global anthropogenic $\mathrm{CH}_{4}$ emissions increased from about 8000 to nearly 9500 megatons of $\mathrm{CO}_{2}$ equivalents, based on GWPs over 100 years (Fernández-Amador et al. 2020b). The sectoral distribution of emissions remained roughly constant over 1997-2014.

It is noteworthy that the bulk of emissions at the sectoral level is concentrated in few countries and regions. For example, the three largest polluters in the respective sectors account for more than half of worldwide $\mathrm{CH}_{4}$ emissions from agriculture (China, India, and Indonesia) and services (the region Rest of Sub-Saharan Africa, China, and India); for about $45 \%$ of $\mathrm{CH}_{4}$ from manufacturing (the region Rest of Middle East, Russia, and China) and from the energy sector (China, Rest of Middle East, and the USA); and for about a third of $\mathrm{CH}_{4}$ from the livestock sector (India, Brazil, and Rest of Sub-Saharan Africa), the transport sector (Russia, USA, and Rest of Middle East), and the public administration sector (China, India, and the USA).

Data on the independent variables included in the regressions are sourced from various datasets. The World Bank's World Development Indicators (WDI) provide data for GDP per capita in constant international dollars, population density, the shares of nuclear energy and fossil fuels in energy production, and fossil rents as share of GDP. Trade openness, measured as imports plus exports as a share of GDP, and value added shares of the agriculture, livestock, energy, manufacturing, service, transport, and public administration sectors are derived from the GTAP database. The political regime index, which ranges from -10 for strongly autocratic to +10 for strongly democratic regimes, is available from the Polity IV database. Table A.1 in the online Appendix provides details on the data sources, while descriptive statistics are provided in Table A.2.

\footnotetext{
5 See Fernández-Amador et al. (2020b) for further details on the contributions of the 57 sectors to total methane emissions.
} 


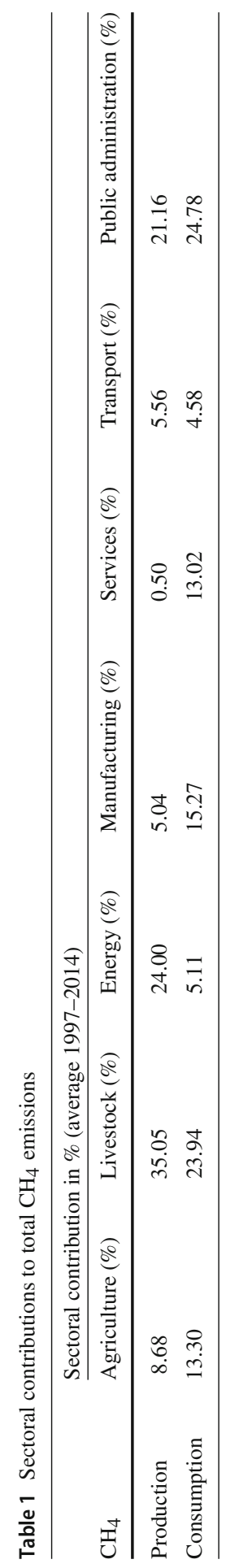




\section{Results}

\subsection{Convergence of economy-wide emissions}

In this section, we analyze convergence of economy-wide emissions toward individualspecific steady states (Table 2, upper panel) and international convergence toward global steady states (Table 2, lower panel). Then, we turn to the sectoral results in Sect. 3.2. ${ }^{6}$

\section{Individual-specific convergence}

The tests for convergence of emissions toward individual-specific steady states (Table 2 , upper panel) provide information on how far a country's emissions are from their steady-state value, and, thus, on the degree to which emission reductions will be associated with transitional dynamics or with the long-run equilibrium growth path. This is informative about the costs of technology adoption for emission abatement. The results of the regressions provide evidence for conditional convergence of emissions within regions toward individual-specific steady states of all four $\mathrm{CH}_{4}$ emission inventories. The estimates of the convergence parameter $\beta$ (i.e., of the logarithm of lagged emissions) are negative and different from zero at the $99 \%$ equal-tailed credible interval (CI). Like for $\mathrm{CO}_{2}$ emissions (see Fernández-Amador et al. 2019), there is no evidence for faster group-specific convergence in EU, OECD, or Annex I countriesthe interactions with the logarithm of lagged emissions are not different from zero at the $90 \% \mathrm{CI}$ and the PIPs are very low.

The implied half-lives - i.e., the time needed to halve the distance between current and steady-state levels of emissions-range from 3.6 (consumption per capita) to 7.1 years (consumption per value added). Thus, $\mathrm{CH}_{4}$ emissions per capita and $\mathrm{CH}_{4}$ intensities are close to their country-specific steady states and emission reduction policies will mainly be related to the long-run equilibrium path of emissions, which implies potentially higher costs for emission abatement. These speeds of convergence are comparable to or slightly slower than those of $\mathrm{CO}_{2}$ emissions (e.g., Westerlund and Basher 2008; Jobert et al. 2010; Fernández-Amador et al. 2019).

For production-based emission inventories, $\mathrm{CH}_{4}$ intensities converge slightly faster than $\mathrm{CH}_{4}$ per capita. Thus, convergence in emission intensities drives the convergence in emissions per capita. By contrast, for consumption-based inventories, $\mathrm{CH}_{4}$ emissions per capita are very close to their steady state, but this result does not appear to be primarily driven by the dynamics in $\mathrm{CH}_{4}$ intensities, which are further away from their steady-state levels. The slower convergence in $\mathrm{CH}_{4}$ intensities of consumption may be driven by changes in the composition of consumption on the one hand, or by changes in the methane-intensity of methods to produce the consumption goods on the other hand-since the $\mathrm{CH}_{4}$ intensity of production shows rather fast convergence, the reason for the slower convergence in $\mathrm{CH}_{4}$ intensities of consumption is likely to be changes in consumption patterns.

\footnotetext{
6 Detailed regression results including the coefficients of the control variables and the instrumental equation, and robustness checks are reported in the online Appendix.
} 
Table 2 Convergence of economy-wide $\mathrm{CH}_{4}$ emissions

\begin{tabular}{|c|c|c|c|c|}
\hline & $\begin{array}{l}(1) \\
\mathrm{CH}_{4} \text { prod pc }\end{array}$ & $\begin{array}{l}(2) \\
\mathrm{CH}_{4} \text { prod per VA }\end{array}$ & $\begin{array}{l}(3) \\
\mathrm{CH}_{4} \text { cons pc }\end{array}$ & $\begin{array}{l}(4) \\
\mathrm{CH}_{4} \text { cons per VA }\end{array}$ \\
\hline \multicolumn{5}{|c|}{ Individual-specific convergence } \\
\hline Ln(emissions) & $-0.1214 * * *$ & $-0.1651 * * *$ & $-0.1735^{* * *}$ & $-0.0932 * * *$ \\
\hline Ln(emissions).EU & 0.0054 & 0.0004 & 0.0000 & 0.0001 \\
\hline Ln(emissions) $\cdot$ OECD & -0.0001 & -0.0003 & -0.0003 & -0.0001 \\
\hline Ln(emissions) Annex I & 0.0000 & 0.0000 & 0.0076 & 0.0003 \\
\hline Ln(income pc) & $0.0273 * *$ & $-0.0604 * * *$ & $0.0551 * * *$ & -0.011 \\
\hline Income pc growth & 0.0987 & $-0.9573 * * *$ & $0.7658 * * *$ & $-0.5942 * *$ \\
\hline Additional controls & Yes & Yes & Yes & Yes \\
\hline Time-dummies & Yes & Yes & Yes & Yes \\
\hline Individual-dummies & Yes & Yes & Yes & Yes \\
\hline PIP EU & 0.1669 & 0.0079 & 0.0172 & 0.0159 \\
\hline PIP OECD & 0.0219 & 0.0086 & 0.0168 & 0.0088 \\
\hline PIP Annex I & 0.0038 & 0.0042 & 0.3359 & 0.0041 \\
\hline Half-life & 5.4 & 3.8 & 3.6 & 7.1 \\
\hline$v$ & 3 & 4 & 4 & 4 \\
\hline DIC & -3708 & -3267 & -3388 & -3235 \\
\hline \multicolumn{5}{|l|}{ Instrumental equation } \\
\hline Constant & $0.0145 * * *$ & $0.0145 * * *$ & $0.0146 * * *$ & $0.0146 * * *$ \\
\hline Income pc growth, lagged & $0.3624 * * *$ & $0.3626 * * *$ & $0.3621 * * *$ & $0.3596 * * *$ \\
\hline \multicolumn{5}{|l|}{ International convergence } \\
\hline Ln(emissions) & -0.0014 & -0.0038 & $-0.0176^{* * *}$ & -0.0016 \\
\hline Ln(emissions) $\cdot \mathrm{EU}$ & -0.0001 & 0.0006 & 0.0001 & -0.0002 \\
\hline Ln(emissions). OECD & 0.0002 & -0.0001 & 0.0002 & 0.0001 \\
\hline Ln(emissions)·Annex I & -0.0002 & -0.0001 & -0.0005 & -0.0004 \\
\hline Ln(income pc) & -0.0026 & 0.0007 & $0.0083 * *$ & 0.0008 \\
\hline Income pc growth & 0.1603 & $-0.7632 * * *$ & $0.4399 * * *$ & -0.2538 \\
\hline Additional controls & Yes & Yes & Yes & Yes \\
\hline Time-dummies & Yes & Yes & Yes & Yes \\
\hline Individual-dummies & No & No & No & No \\
\hline PIP EU & 0.0052 & 0.0019 & 0.0071 & 0.0017 \\
\hline PIP OECD & 0.0031 & 0.0037 & 0.0068 & 0.0090 \\
\hline PIP Annex I & 0.0035 & 0.0077 & 0.0248 & 0.0018 \\
\hline Half-life & 494.8 & 182.1 & 39 & 432.9 \\
\hline$v$ & 3 & 4 & 4 & 4 \\
\hline DIC & -3726 & -3278 & -3479 & -3313 \\
\hline
\end{tabular}


Table 2 continued

\begin{tabular}{|c|c|c|c|c|}
\hline & $\begin{array}{l}\text { (1) } \\
\mathrm{CH}_{4} \text { prod pc }\end{array}$ & $\begin{array}{l}(2) \\
\mathrm{CH}_{4} \text { prod per VA }\end{array}$ & $\begin{array}{l}(3) \\
\mathrm{CH}_{4} \text { cons pc }\end{array}$ & $\begin{array}{l}(4) \\
\mathrm{CH}_{4} \text { cons per VA }\end{array}$ \\
\hline \multicolumn{5}{|l|}{ Instrumental equation } \\
\hline Constant & $0.0145^{* * *}$ & $0.0145 * * *$ & $0.0145 * * *$ & $0.0146 * * *$ \\
\hline Income pc growth, lagged & $0.3628 * * *$ & $0.3616^{* * * *}$ & $0.3641 * * *$ & $0.3607 * * *$ \\
\hline
\end{tabular}

*CI $90 \%, * *$ CI 95\%, ***CI 99\% where CI stands for the equal-tailed credible interval. $N=390$ observations. All variables but group dummies and income pc growth enter in lagged values. The half-life is calculated as $\ln (0.5) / \ln (1+\beta)$. v measures the degree of cross-sectional heteroscedasticity; it governs the distribution of individual-specific weights of the scale mixture of normals, corresponding to a t-student distribution with $v$ degrees of freedom (see Fernández-Amador et al. 2019). The deviance information criterion (DIC) is computed as $D I C=\hat{D}_{q}+\operatorname{Var}\left(D_{q}\right) / 2$, where $D_{q}$ is the deviance measure associated with draw $q$ in the Markov Chains (see Spiegelhalter 2002; Gelman et al. 2004, Chap. 7). Results are based on 3 Markov Chains with 750,000 iterations each, after a burn-in of 750,000, from which every third draw is retained. More detailed results are reported in the online appendix (Tables A.3 and A.4)

Income per capita and its growth rate increase the growth rate of $\mathrm{CH}_{4}$ emissions per capita and decrease the growth rate of $\mathrm{CH}_{4}$ per value added. That is, income growth leads to a reduction in $\mathrm{CH}_{4}$ intensity but also to an expansion of economic activity that counterbalances and outweighs this methane-efficiency gain, such that the growth rate of $\mathrm{CH}_{4}$ per capita is larger at higher income levels. This is consistent with the predictions of the model by Ordás Criado et al. (2011) and may also explain the lack of empirical evidence for a negative slope in the income- $\mathrm{CH}_{4}$ relationship, both over time (Jorgenson and Birkholz 2010) and at higher income levels (Fernández-Amador et al. 2018), which the environmental Kuznets' curve hypothesis predicts.

\subsubsection{International convergence across regions}

Turning to international convergence across countries (Table 2, lower panel), the estimates for $\beta$ are not different from zero at the $90 \%$ CI but for consumption-based emissions per capita. Thus, only $\mathrm{CH}_{4}$ per capita embodied in consumption converges across countries, while there is no evidence for international convergence of the other emission inventories. This contrasts with the findings of some empirical studies on $\mathrm{CO}_{2}$ emissions, which find evidence for convergence (e.g., Nguyen 2005; Westerlund and Basher 2008; Brock and Taylor 2010; Fernández-Amador et al. 2019). Also, the implied half-life for $\mathrm{CH}_{4}$ per capita embodied in consumption, the only inventory for which we found convergence, is with 39 years much longer than the 15 years found for $\mathrm{CO}_{2}$ emissions by Fernández-Amador et al. (2019). Again, there is no evidence for faster group-specific convergence of $\mathrm{CH}_{4}$ emissions, as the parameters associated with the interaction terms are not different from zero and their PIPs are very low. Interestingly, the effects of income per capita and its growth rate disappear for some emission inventories. The largely missing evidence for cross-country convergence of aggregate $\mathrm{CH}_{4}$ emissions, especially for production-based emissions, questions the potential to achieve multilateral agreements for methane. ${ }^{7}$

\footnotetext{
7 The very low estimates for $v$ throughout all regressions, which are robust to specifying alternative priors for $v$ (see Sect. A.4 in the online appendix), indicate the presence of heteroscedasticity. A sensitivity
} 
The convergence of consumption-based emissions per capita is not associated with convergence of consumption-based emission intensities. In this sense, the convergence of emissions per capita is unlikely to be driven by converging consumption bundles across countries and may be related to the importation of products produced elsewhere as a result of income effects that impact on the scale of consumption. Furthermore, the absence of international convergence of $\mathrm{CH}_{4}$ emissions released from production may result from persistent sectoral specialization patterns. If production structures only change very slowly, the concentration of $\mathrm{CH}_{4}$ emissions in specific economic sectors may account for differences in $\mathrm{CH}_{4}$ releases that persist over time. In the next subsection, we explore sector-specific convergence patterns in order to provide additional insights to interpret the economy-wide findings.

\subsection{Convergence of sectoral emissions}

\subsubsection{Individual-specific convergence}

The results from the sectoral convergence tests toward individual-specific steady states are summarized in Table 3. The upper two panels show the results for $\mathrm{CH}_{4}$ per capita and per unit of value added released from production, and the lower two panels refer to emissions embodied in consumption. ${ }^{8}$

In line with the finding for aggregate emissions, there is strong evidence for convergence to individual-specific steady states for all methane inventories in all sectors, as shown by the posterior estimates of $\beta$, which are negative and different from zero at the $99 \%$ CI throughout. The speed of convergence and the implied half-lives at the sectoral level explain the findings at the economy-wide level. For most sectors and inventories, the half-lives range from 2.3 to 4.6 years. The exceptions are methane per capita from production in public administration, with a half-life of 10 years, and consumption-based methane intensities in all sectors, with half-lives up to 53 years in services. The relatively large contribution of public administration to economy-wide emissions (over 20\%, see Table 1) explains the relatively slower speed of convergence found in $\mathrm{CH}_{4}$ per capita from production economy-wide. By contrast, the relatively long half-life of consumption-based $\mathrm{CH}_{4}$ intensity found economy-wide is explained by the slow convergence of consumption-based $\mathrm{CH}_{4}$ intensity estimated in all sectors. Especially the long half-lives in the service, manufacturing, transport, and livestock sectors indicate that consumption patterns from these sectors are subject to change.

Notably, certain economic sectors are characterized by group-specific convergence of $\mathrm{CH}_{4}$ emissions in Annex I countries on the one hand, and OECD countries on the other hand, which contributes further detail to the economy-wide findings. Yet, these group-specific convergence dynamics are only present in few economic sectors, and thus, they are too weak to show up in the economy-wide results summarized above.

Footnote 7 continued

analysis for different exogenously set values of $v$ emphasizes that the main results are robust across a wide range of values (Table A.13 in the online appendix). Only the convergence term of $\mathrm{CH}_{4}$ per value added of production becomes different from zero at the $90 \%$ CI for values for $v$ of 20 or higher, indicating very slow convergence toward global steady states.

8 More detailed results are available in Tables A.5-A.8 in the online appendix. 


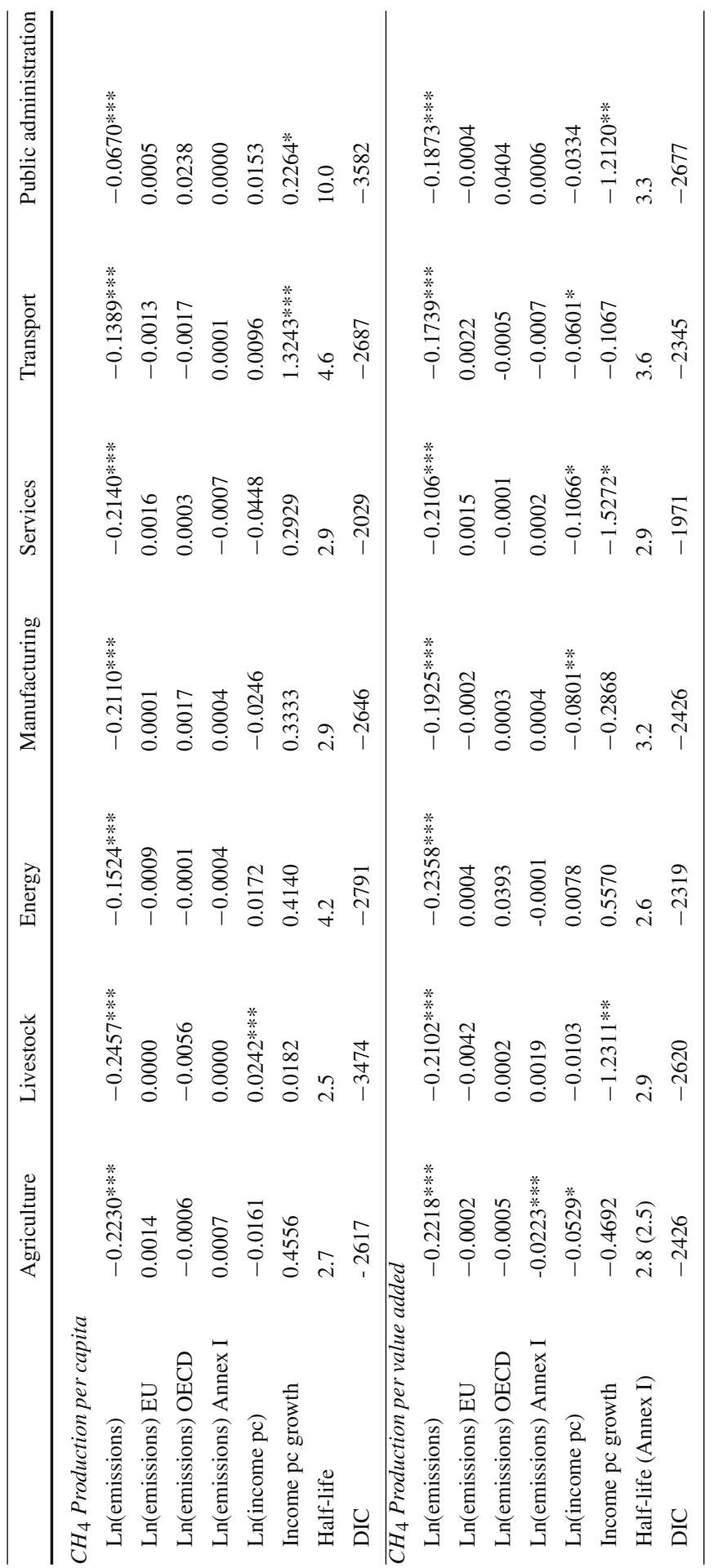




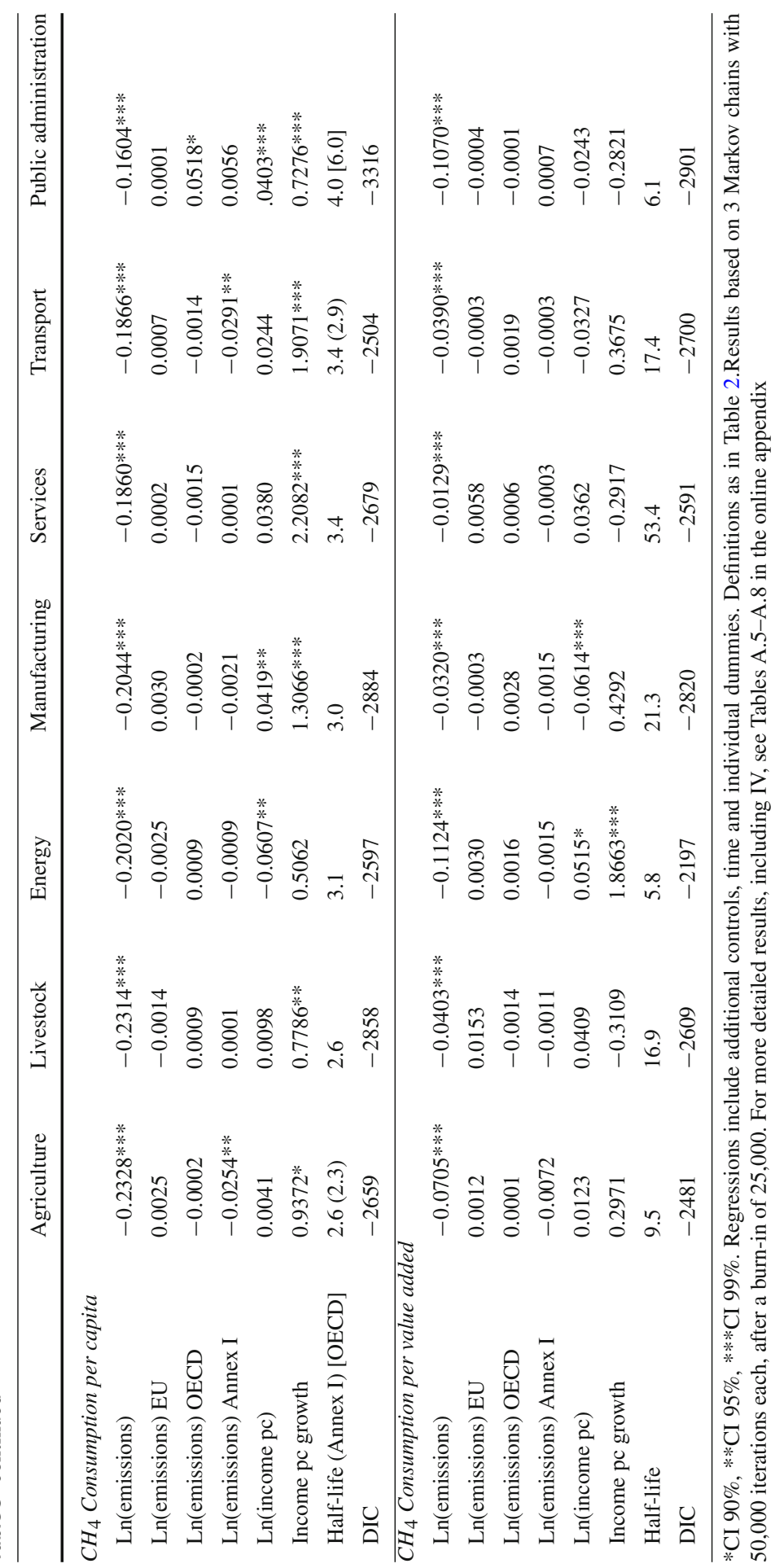


On the one side, Annex I countries show faster convergence of $\mathrm{CH}_{4}$ emissions from agriculture $\left(\mathrm{CH}_{4}\right.$ intensity of production and $\mathrm{CH}_{4}$ per capita consumption) and from the transport sector $\left(\mathrm{CH}_{4}\right.$ per capita consumption). Thus, the lower $\mathrm{CH}_{4}$ intensity of agricultural production in Annex I countries observed in our data may be related to these differential (faster) convergence dynamics, whereas in non-Annex I countries the transition to lower $\mathrm{CH}_{4}$ intensities is slower. Yet, the detected differential may also be related to heterogeneous sectoral specialization within the agriculture sector. In this sector, methane releases are mainly caused by rice cultivation, which accounts for only a small and decreasing share of agricultural activities in Annex I countries.

Turning to the consumption-based inventories, the speed of convergence of $\mathrm{CH}_{4}$ intensity is similar across Annex I and non-Annex I countries in all sectors. Thus, the faster speed of convergence of $\mathrm{CH}_{4}$ per capita in the agriculture and transport sectors in Annex I countries is likely to be driven by the scale of consumption, which appears to be closer to its steady-state level as compared to that of non-Annex I countries. On the other side, OECD countries exhibit slower convergence of consumption-based emissions per capita from public administration. The specific dynamics in OECD countries seem to be also related to the scale of consumption of goods and services from the public sector, since such a differential is not present when looking at consumptionbased $\mathrm{CH}_{4}$ intensity.

Similar to the economy-wide estimates, income per capita and its growth rate are connected to a higher growth rate of emissions per capita but to lower growth rate of methane intensities, whenever their effect is different from zero. The only exception is the energy sector, where for consumption-based emissions there is some evidence of the opposite effect. This suggests that in faster growing economies consumption from the energy sector may shift toward more oil and gas intensive products, such that $\mathrm{CH}_{4}$ intensity increases. It also suggests that in periods of faster economic growth the income-elasticity of consumption from the energy sector is lower, which explains the lower growth rate of $\mathrm{CH}_{4}$ per capita embodied in consumption. Overall, the income terms are different from zero more often for consumption-based than for productionbased emissions per capita, whereas the opposite is true for methane intensities. This is in line with the slightly larger income-elasticity of economy-wide consumptionbased relative to production-based per capita emissions found by Fernández-Amador et al. (2018) and the smaller income-elasticity of methane intensity of consumption generally found in sectoral estimations by Fernández-Amador et al. (2020a).

\subsubsection{International convergence across regions}

The results of the test for international convergence of sectoral methane emissions across regions are shown in Table 4. Although at the economy-wide level (in Sect. 3.1) there is no evidence for international convergence of most of the aggregate $\mathrm{CH}_{4}$ inventories, the sectoral estimates suggest that emissions from many economic sectors converge toward global steady states, conditional on economic and political factors. More specifically, there is international convergence for all $\mathrm{CH}_{4}$ inventories, with the exception of $\mathrm{CH}_{4}$ per capita from production in livestock, energy, and transport, and the $\mathrm{CH}_{4}$ intensity of consumption in agriculture, manufacturing, and services. The public administration sector only shows convergence toward global steady states for 
$\mathrm{CH}_{4}$ per capita embodied in consumption. The speed of convergence (and divergence) varies across sectors but is slow in general, with half-lives ranging from 8 to 187 years.

Since there is convergence of $\mathrm{CH}_{4}$ per capita embodied in consumption in all economic sectors, this convergence shows up in the economy-wide results on aggregate emissions. For the remaining inventories, the sectors for which we detect international convergence account for $14 \%\left(\mathrm{CH}_{4}\right.$ per capita from production), $34 \%\left(\mathrm{CH}_{4}\right.$ intensity of consumption), and $79 \%\left(\mathrm{CH}_{4}\right.$ intensity of production) of overall emissions, respectively (see Table 1). Although this share is high for the $\mathrm{CH}_{4}$ intensity of production, the OECD group shows some (weak) evidence of divergence in the public administration sector, such that there is no evidence for global convergence of emissions economywide. Again, we do not find evidence for faster group-specific convergence for EU, OECD, or Annex I countries.

The $\mathrm{CH}_{4}$ intensities of production may converge across countries in most sectors, because countries with larger potential for methane efficiency improvements are catching up with more methane-efficient countries. This is in line with the overall decrease in methane intensity observed in the period covered in our sample. Yet, the estimated half-lives are relatively long, emphasizing a slow catch-up process. Nevertheless, as can be concluded from the economy-wide results on aggregate emissions, higher demand induced by global income expansion increases production-based emissions per capita, which seems to work against convergence forces. This scale effect is sizable and counteracts the convergence dynamics of $\mathrm{CH}_{4}$ intensities in sectors comprising methane-intensive activities, such as cattle breeding in the livestock sector, drilling and transportation of fossil fuels in the energy and transport sectors, respectively, and waste management in the public administration sector (see Fernández-Amador et al. 2020b). Even though rice cultivation is $\mathrm{CH}_{4}$ intensive, it only accounts for about $6 \%$ of value added from the agriculture sector, what may explain that there is some evidence for convergence of $\mathrm{CH}_{4}$ per capita from agricultural production (90\% CI). By contrast, the activities in the manufacturing sector account for only a small share of aggregate $\mathrm{CH}_{4}$ releases (see Table 1). There, the scale effect of increased production does not outweigh the convergence forces of $\mathrm{CH}_{4}$ intensities. Moreover, in the services sector, which accounts for merely $0.5 \%$ of aggregate emissions, the scale effect seems to strengthen convergence forces, such that the half-life is shorter for emissions per capita than for emission intensity.

Turning to consumption-based emissions, the convergence of $\mathrm{CH}_{4}$ embodied in consumption per capita, detected for all sectors, is not driven by convergence in $\mathrm{CH}_{4}$ intensities of consumption. $\mathrm{CH}_{4}$ intensities of consumption are largely determined by the composition of consumption bundles and tastes. Consumer tastes and consumption patterns are usually rigid and to a large degree region specific (York and Gossard 2004; World Bank Group 2015), which may explain the absence of international convergence of $\mathrm{CH}_{4}$ intensities of consumption detected in many sectors. Our results suggest, however, that there may be some assimilation in consumer tastes across countries in terms of demand for meat (livestock sector; see also York and Gossard 2004; Fiala 2008) and energy (energy and transport sectors), which shows up in converging $\mathrm{CH}_{4}$ intensities of consumption from these sectors.

Finally, the income terms are estimated to be different from zero in about half of the regressions. In these cases, and as expected, increasing income is connected to a higher 


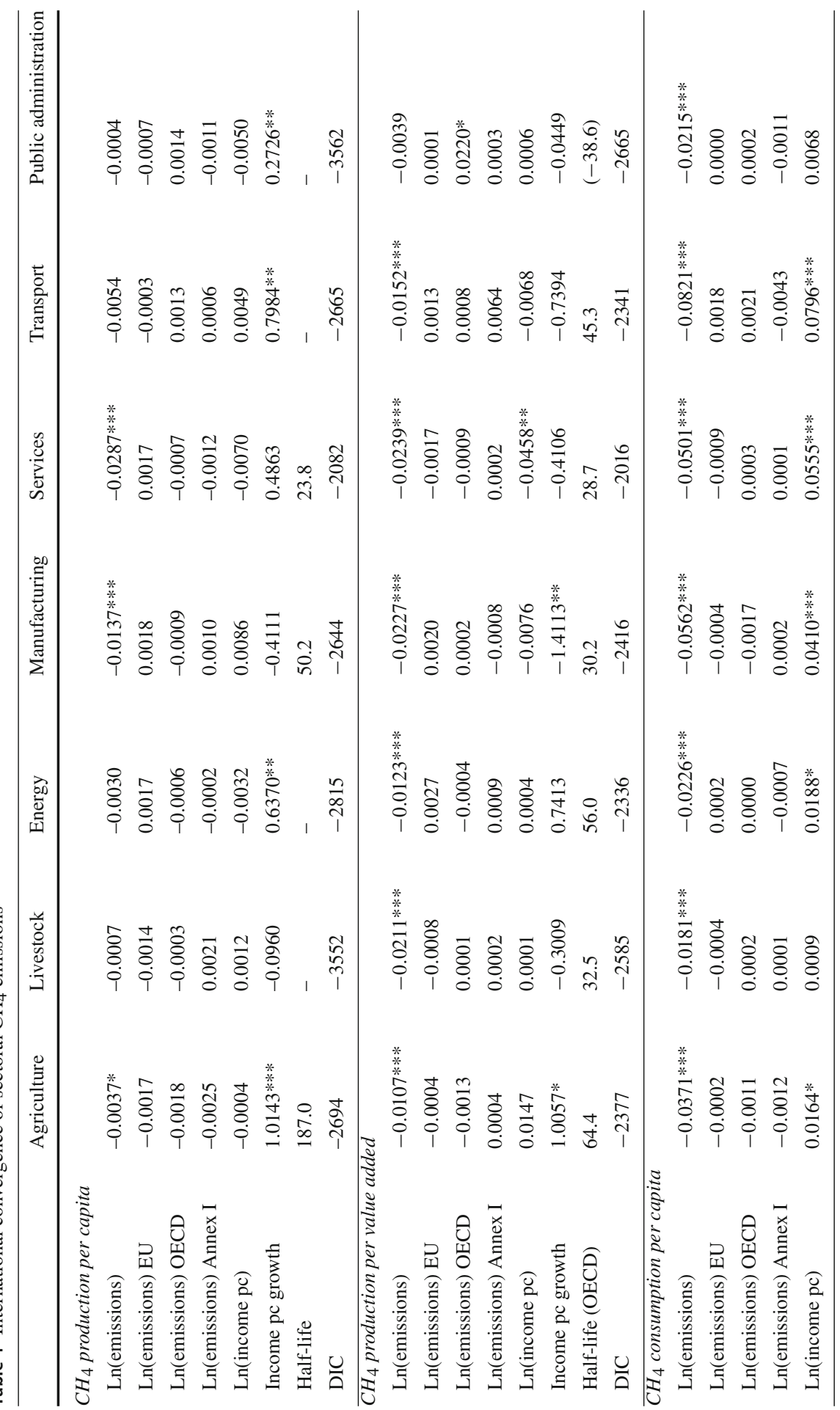




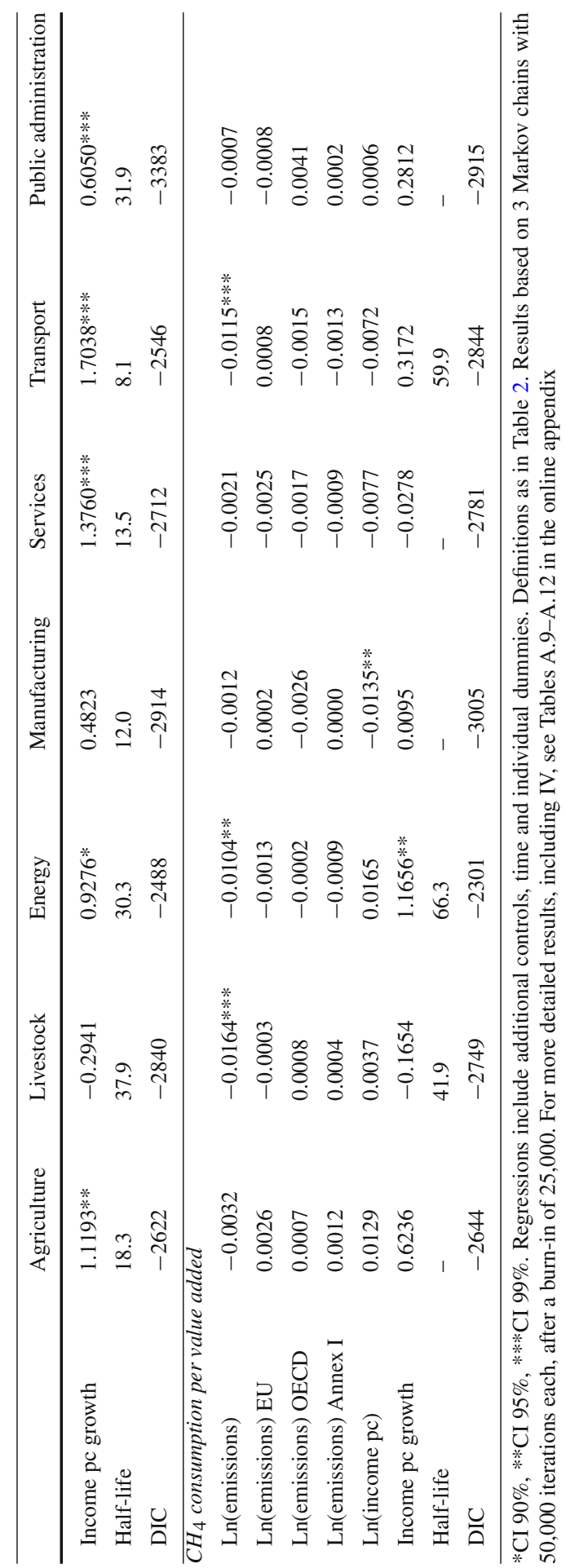


growth rate of emissions per capita and to a lower growth rate of $\mathrm{CH}_{4}$ intensities. One exception is again the energy sector, and there is slight evidence that the $\mathrm{CH}_{4}$ intensity of agricultural production increases faster (or decreases slower) if GDP per capita grows faster $(90 \% \mathrm{CI}){ }^{9}$

\section{Conclusion}

In this study, we conducted a comprehensive analysis of convergence patterns of $\mathrm{CH}_{4}$ emissions based on international data on anthropogenic $\mathrm{CH}_{4}$ emissions, which contributes several insights to the literature on the sustainability of GHG emissions and provides information for international policy dialogue.

First, our results show that methane emissions per capita and $\mathrm{CH}_{4}$ intensities are stabilizing rapidly around individual-specific steady states. The estimated short halflives of $\mathrm{CH}_{4}$ emissions (3.6-7.1 years) suggest that the steady-state level of emissions will not differ substantially from current levels. Since countries are already close to their steady-state levels of emissions, it is unlikely that methane releases will decrease substantially in the absence of policies specifically aimed at improvements in methane efficiency.

Although we find economic growth and development to be related to methaneefficiency gains - i.e., reductions of emissions per unit of value added-these gains do not counterbalance the effects of income expansion, which are reflected in rising $\mathrm{CH}_{4}$ emissions per capita. This underlines the importance of policies to actively reduce $\mathrm{CH}_{4}$ emissions, which could limit global warming in the near term (Jackson 2009; Shindell et al. 2012, 2017). Such policies may aim at improved water management in rice cultivation, nutritional changes of ruminants, adaptation of manureand waste management systems, programs to reduce meat consumption, increased efforts to recover methane in coal production, reducing methane leakage by intensified inspections in oil and gas production and transportation, or the promotion of renewable energy sources (see Michaelowa and Dransfeld 2008; Fumoto et al. 2010; Höglund-Isaksson 2012; Gerber et al. 2013; Cowley and Brorsen 2018).

Second, our results do not provide evidence for international convergence of $\mathrm{CH}_{4}$ emissions. This is a consequence of the concentration of $\mathrm{CH}_{4}$ emissions in specific economic sectors and persistent patterns of economic specialization. Countries specialized in methane-intensive economic sectors may face difficulties to reduce their methane emissions, especially if demand for these sectors is increasing. This may explain why Argentina, Brazil, and Uruguay, all having large livestock sectors, have been particularly concerned with the specific treatment of $\mathrm{CH}_{4}$ emissions in international cooperation mechanisms under Article 6 of the Paris agreement (see Carbon Brief 2019). Furthermore, despite persistent production structures, $\mathrm{CH}_{4}$ emissions embodied in consumption per capita converge across countries, as a result of international trade. This difference in emission dynamics between production- and consumption-

\footnotetext{
9 The evidence shown for agriculture seems to be driven by the fast growth rate of China, a large rice producer, since the international convergence regressions do not account for individual-specific effects. In the period covered in the data, the $\mathrm{CH}_{4}$ intensity of agricultural production in China decreased more slowly in periods of higher economic growth.
} 
based per capita emissions highlights the relevance of the discussion about whether producers or consumers should be held responsible for emissions.

Third, at the sectoral level, we document important differences in international convergence dynamics between $\mathrm{CH}_{4}$ emissions per capita and $\mathrm{CH}_{4}$ intensities and between production- and consumption-based emissions. For production-based emissions, $\mathrm{CH}_{4}$ intensities converge across countries in most economic sectors, suggesting that $\mathrm{CH}_{4}$-intensive countries are catching up in terms of the $\mathrm{CH}_{4}$ efficiency of production. Yet, international convergence in $\mathrm{CH}_{4}$ per capita released from production is absent in methane-intensive sectors such as livestock, energy, transport, and public administration. This absence of convergence stems from the rather rigid nature of economic specialization patterns and the concentration of methane-intensive industries in few countries. In this context, rising global demand, which is met by expanding production, will especially increase emissions in countries that are specialized in methane-intensive industries. In this sense, national policies that target territorial emissions, such as the policies defined within the framework of NDCs, may not be effective in limiting territorial emissions per capita, which will be affected by expansions in global demand; national regulation could be more effective in lowering the emission intensity of production. Policies aimed at production-based emission intensities could be supplemented by policies that target consumption-based emissions per capita. In this vein, our result that consumption-based emissions per capita converge across countries suggests that policies targeted at consumption-based emissions may generate less concerns from an equity perspective and facilitate negotiations about a global climate policy framework.

International negotiations on the implementation of global markets for GHGs have not been successful so far. Negotiations at the COP25 in Madrid on the set-up of a global emission trading system have failed, in part because negotiators did not agree on the specific treatment of $\mathrm{CH}_{4}$ emissions in aggregate GHG budgets (Carbon Brief 2019). Given the specificity of methane and the remarkable differences it shows with respect to $\mathrm{CO}_{2}$, it seems appropriate to think about its separate treatment. In this regard, there is a trade-off between economic efficiency, which calls for regulation of aggregate GHG baskets, and voluntary participation in and compliance with international agreements, which could be better achieved by a separate and sector-specific treatment of $\mathrm{CH}_{4}$ emissions (see Barrett 2008b). On the one side, the main economic argument in favor of aggregating different GHGs together and making baskets of $\mathrm{CO}_{2}$ equivalents subject to emission trading is that this approach allows emissions to be reduced where the marginal costs of abatement are the lowest. On the other side, treating different GHGs separately may increase the probability to reach an agreement on the implementation of global markets for emissions. A separate agreement for $\mathrm{CH}_{4}$ emissions could promote the voluntary participation of countries by reducing uncertainty connected to the conversion of $\mathrm{CH}_{4}$ emissions to $\mathrm{CO}_{2}$ equivalents. At the same time, a differentiated treatment of GHGs may allow policy makers to adapt climate policies more closely to the specific nature of different GHGs (see, e.g., Jackson 2009; Shindell et al. 2017; Fernández-Amador et al. 2020b). 
Furthermore, the differences in the processes that generate methane emissions, which are characterized by different abatement potentials, and the specializationrelated differences in emission dynamics across countries suggest that a strategy based on sector-specific regulation could be justified. Given the current deadlock of negotiations on the implementation of global carbon markets to operationalize the Paris Agreement, the possibility of designing specific agreements for $\mathrm{CH}_{4}$ should be considered. Moreover, the bulk of emissions at the sectoral level is concentrated in few countries, thus reducing the number of negotiators with strong policy preferences. Therefore, a sector-specific treatment of $\mathrm{CH}_{4}$ emissions may facilitate reaching consensus on targets, voluntary participation in the agreement, and compliance with its content, what is particularly relevant because of the horizontal nature of international law (see Barrett 2008a, b).

Supplementary Information The online version contains supplementary material available at https://doi. org/10.1007/s00181-021-02162-9.

Funding Open access funding provided by University of Innsbruck and Medical University of Innsbruck. This study was funded by the NRP 73 project Switzerland's Sustainability Footprint: Economic and Legal Challenges (Grant Number 407340-172437) University of Bern, supported by the Swiss National Science Foundation (SNSF) within the framework of the National Research Programme "Sustainable Economy: resource-friendly, future-oriented, innovative" (NRP 73).

\section{Declarations}

Conflict of interest All authors declare that they have no conflict of interest.

Ethical approval This article does not contain any studies with human participants or animals performed by any of the authors.

Open Access This article is licensed under a Creative Commons Attribution 4.0 International License, which permits use, sharing, adaptation, distribution and reproduction in any medium or format, as long as you give appropriate credit to the original author(s) and the source, provide a link to the Creative Commons licence, and indicate if changes were made. The images or other third party material in this article are included in the article's Creative Commons licence, unless indicated otherwise in a credit line to the material. If material is not included in the article's Creative Commons licence and your intended use is not permitted by statutory regulation or exceeds the permitted use, you will need to obtain permission directly from the copyright holder. To view a copy of this licence, visit http://creativecommons.org/licenses/by/4.0/.

\section{References}

Aichele R, Felbermayr G (2012) Kyoto and the carbon footprint of nations. J Environ Econ Manag 63:336354

Aichele R, Felbermayr G (2015) Kyoto and carbon leakage: an empirical analysis of the carbon content of bilateral trade. Rev Econ Stat 97(1):104-115

Aldy J (2006) Per capita carbon dioxide emissions: convergence or divergence? Environ Resour Econ 33:533-555

Barassi M, Cole MA, Elliott RJ (2008) Stochastic divergence or convergence of per capita carbon dioxide emissions: re-examining the evidence. Environ Resour Econ 40:121-137 
Barassi MR, Cole MA, Elliott RJ (2011) The stochastic convergence of $\mathrm{CO}_{2}$ emissions: a long memory approach. Environ Resour Econ 49:367-385

Barrett S (2008) Climate treaties and the imperative for enforcement. Oxf Rev Econ Policy 24:239-258

Barrett S (2008) An economic theory of international environmental law. Oxford University Press, Oxford

Barro R, Sala-i-Martin X (2004) Economic growth, 2nd edn. MIT Press, Massachusetts

Bernard A, Durlauf S (1996) Interpreting tests of the convergence hypothesis. J Econ 71(1-2):161-173

Blanco G, Gerlagh R, Suh S, Barrett J, de Coninck HC, Morejon CFD, Mathur R, Nakicenovic N, Ahenkora AO, Pan J, Pathak H, Rice J, Richels R, Smith SJ, Stern DI, Toth FL, Zhou P (2014) Climate change 2014: mitigation of climate change. Contribution of working group III to the fifth assessment report of the intergovernmental panel on climate change. Cambridge University Press, Ch. 5: Drivers, Trends and Mitigation, pp 351-411

Brock W, Taylor M (2010) The Green Solow model. J Econ Growth 15:127-153

Camarero M, Castillo J, Picazo AJ, Tamarit C (2013) Eco-efficiency and convergence in OECD countries. Environ Resour Econ 55:87-106

Carbon Brief (2019) COP25: key outcomes agreed at the UN climate talks in Madrid

Cowley C, Brorsen BW (2018) Anearobic digester production and cost functions. Ecol Econ 152:347-357

Davis S, Caldeira K (2010) Consumption-based accounting of $\mathrm{CO}_{2}$ emissions. PNAS Proceedings of the National Academy of Sciences of the United States of America, 1-6

Fernández-Amador O, Francois JF, Oberdabernig DA, Tomberger P (2017) Carbon dioxide emissions and economic growth: an assessment based on production and consumption emission inventories. Ecol Econ 135:269-279

Fernández-Amador O, Francois JF, Oberdabernig DA, Tomberger P (2018) Empirical estimates of the methane-income elasticity. Econ Lett 171:137-139

Fernández-Amador O, Francois JF, Oberdabernig DA, Tomberger P (2020a) Economic growth, sectoral structures, and environmental methane footprints. Appl Econ 52(13)

Fernández-Amador O, Francois JF, Oberdabernig DA, Tomberger P (2020b) The methane footprint of nations: stylized facts from a global panel dataset. Ecol Econ 170

Fernández-Amador O, Francois JF, Tomberger P (2016) Carbon dioxide emissions and international trade at the turn of the millennium. Ecol Econ 125:14-26

Fernández-Amador O, Oberdabernig D, Tomberger P (2019) Testing for convergence in carbon dioxide emissions using a Bayesian robust structural model. Environ Resour Econ 73(4):1265-1286

Fesenfeld LP, Schmidt TS, Schrode A (2018) Climate policy for short- and long-lived pollutants. Nat Clim Chang 8:924-936

Fiala N (2008) Meeting the demand: an estimation of potential future greenhouse gas emissions from meat production. Ecol Econ 67:412-419

Frankel J, Rose A (2005) Is trade good for the environment? Sorting out the causality. Rev Econ Stat 87:85-91

Fumoto T, Yanagihara T, Saito T, Yagi K (2010) Assessment of the methane mitigation potentials of alternative water regimes in rice fields using a process-based biogeochemistry model. Glob Change Biol 16:1847-1859

Gelman A, Carlin JB, Stern HS, Rubin DB (2004) Bayesian data analysis: second edition. Texts in statistical science. CRC Press, Boca Raton

Gelman A, Goodrich B, Gabry J, Ali I (2017) R-squared for Bayesian regression models, unpublished manuscript, Department of Statistics, Columbia University

George EI, McCulloch RE (1993) Variable selection via Gibbs sampling. J Am Stat Assoc 88:881-889

Gerber P, Steinfeld H, Henderson B, Mottet A, Opio C, Dijkman J, Falcucci A, Tempio G (2013) Tackling climate change through livestock. A global assessment of emissions and mitigation opportunities. Food and Agriculture Organization of the United Nations (FAO), Rome

Höglund-Isaksson L (2012) Global anthropogenic methane emissions 2005-2030: technical mitigation potentials and costs. Atmos Chem Phys 12(19):9079-9096

IPCC (2014) Climate Change 2014: synthesis report. Contribution of working groups I, II and III to the fifth assessment report of the intergovernmental panel on climate change. IPCC, Geneva, Switzerland

Jackson SC (2009) Parallel pursuit of near-term and long-term climate mitigation. Science 326:526-527

Jacquet J, Jamieson D (2016) Soft but significant power in the Paris agreement. Nat Clim Chang 6:643-645

Jobert T, Karanfil F, Tykhonenko A (2010) Convergence of per capita carbon dioxide emissions in the EU: legend or reality? Energy Econ 32:1364-1373 
Jorgenson A, Birkholz R (2010) Assessing the causes of anthropogenic methane emissions in comparative perspective, 1990-2005. Ecol Econ 69:2634-2643

Karakaya E, Yilmaz B, Alatas S (2019) How production-based and consumption-based emissions accounting systems change climate policy analysis: the case of $\mathrm{CO}_{2}$ convergence. Environ Sci Pollut Res 26:16682-16694

Keohane RO, Victor DG (2016) Cooperation and discord in global climate policy. Nat Clim Chang 6:570575

Lenzen M, Kanemoto K, Moran D, Geschke A (2012) Mapping the structure of the world economy. Environ Sci Technol 46:8374-8381

Lopes H, Polson N (2014) Bayesian instrumental variables: priors and likelihoods. Econ Rev 33:100-121

Michaelowa A, Dransfeld B (2008) Greenhouse gas benefits of fighting obesity. Ecol Econ 66:298-309

Nguyen PV (2005) Distribution dynamics of $\mathrm{CO}_{2}$ emissions. Environ Resour Econ 32:495-508

Nieto J, Carpintero O, Miguel LJ (2018) Less than $2{ }^{\circ} \mathrm{C}$ ? An economic-environmental evaluation of the Paris agreement. Ecol Econ 146:69-84

Nourry M (2009) Re-examining the empirical evidence for stochastic convergence of two air pollutants with a pair-wise approach. Environ Resour Econ 44:555-570

Ordás Criado C, Grether J-M (2011) Convergence in per capita $\mathrm{CO}_{2}$ emissions: a robust distributional approach. Resour Energy Econ 33:637-665

Ordás Criado C, Valente S, Stengos T (2011) Growth and pollution convergence: theory and evidence. J Environ Econ Manag 62:199-214

Panopoulou E, Pantelidis T (2009) Club convergence in carbon dioxide emissions. Environ Resour Econ 44:47-70

Peters G (2008) From production-based to consumption-based national emission inventories. Ecol Econ 65:13-23

Peters G, Hertwich E (2008) Post-Kyoto greenhouse gas inventories: production vs. consumption. Clim Change 86:51-55

Pettersson F, Maddison D, Acar S, Söderholm P (2014) Convergence of carbon dioxide emissions: a review of the literature. Int Rev Environ Resour Econ 7:141-178

Richmond A, Kaufmann R (1997) Is there a turturn point in the relationship between income and energy use and/or carbon emissions? Ecol Econ 56:176-189

Romero-Ávila D (2008) Convergence in carbon dioxide emissions among industrialised countries revisited. Energy Econ 30:2265-2282

Rogelj J, den Elzen M, Höhne N, Fransen T, Fekete H, Winkler H, Schaeffer R, Sha F, Riahi K, Meinshausen M (2016) Paris agreement climate proposals need a boost to keep warming well below $2{ }^{\circ} \mathrm{C}$. Nature 534:631-639

Shindell D, Borgford-Parnell N, Brauer M, Haines A, Kuylenstierna JCI, Leonard SA, Ramanathan V, Ravishankara A, Amann M, Srivastava L (2017) A climate policy pathway for near- and long-term benefits. Science 356(6337):493-494

Shindell D, Kuylenstierna JCI, Vignati E, van Dingenen R, Amann M, Klimont Z, Anenberg SC, Muller N, Janssens-Maenhout G, Raes F, Schwartz J, Faluvegi G, Pozzoli L, Kupiainen K, Höglund-Isaksson L, Emberson L, Streets D, Ramanathan V, Hicks K, Oanh NTK, Milly G, Williams M, Demkine V, Fowler D (2012) Simultaneously mitigating near-term climate change and improving human health and food security. Science 335(6065):183-189

Spiegelhalter David J, Best NGCBP, v. d. L. A., (2002) Bayesian measures of model complexity and fit (with discussion). J R Stat Soc Ser B 64:583-639

Stern D (2017) The environmental Kuznets curve after 25 years. J Bioecon 1-22

Strazicich MC, List JA (2003) Are $\mathrm{CO}_{2}$ emission levels converging among industrial countries? Environ Resour Econ 24:263-271

Westerlund J, Basher SA (2008) Testing for convergence in carbon dioxide emissions using a century of panel data. Environ Resour Econ 40:109-120

Wiedmann T (2009) A review of recent multi-region input-output models used for consumption-based emission and resource accounting. Ecol Econ 69:211-222

Wiedmann T, Wilting H, Lenzen M, Lutter S, Plam V (2011) Quo vadis MRIO? Methodological, data and institutional requirements formulti-region input-output analysis. Ecol Econ

Wiedmann TO, Schandl H, Lenzen M, Moran D, Suh S, West J, Kanemoto K (2015) The material footprint of nations. Proc Natl Acad Sci USA 112(20):6271-6276 
World Bank Group (2015) Purchasing power parities and the real size of world economies. The World Bank Group, Ch. 4: methodologies used to calculate regional and global PPPs, pp 203-215

Yavuz N, Yilanci V (2013) Convergence in per capita carbon dioxide emissions among G7 countries: a TAR panel root approach. Environ Resour Econ 54:283-291

York R, Gossard MH (2004) Cross-national meat and fish consumption: exploring the effects of modernization and ecological context. Ecol Econ 48:293-302

Publisher's Note Springer Nature remains neutral with regard to jurisdictional claims in published maps and institutional affiliations. 